\title{
Insurance Expansions: Do They Hurt Those They Are Designed To Help?
}

Equalizing insurance benefits might translate into more services for the privileged and added burdens for the vulnerable.

\section{by Barak D. Richman}

ABSTRACT: Seeking to redress health disparities across income and race, many policymakers mandate health insurance benefits, presuming that equalized benefits will help equalize use of beneficial health services. This paper tests that presumption by measuring health care use by a diverse population with comprehensive health insurance. Focusing on use of mental health care and pharmaceuticals, it finds that even when insurance benefits and access are constant, whites and those with high incomes consume more of these benefits than other people do. This suggests that privileged classes extract more health care services even when everyone pays equal premiums for equal insurance coverage. [Health Affairs 26, no. 5 (2007): 1345-1357; 10.1377/hlthaff.26.5.1345]

$\mathrm{H}$ EALTH Disparities along RACE AND CLASS lines, in which lowincome and nonwhite people consistently exhibit poorer average health outcomes than wealthy whites, have appropriately prompted attention from academics and policymakers. One popular policy response is to mandate insurance benefits across the population. Growing concern over disparities in mental health, for example, was one motive behind Congress's passage and extension of the Mental Health Parity Act of 1996. Most states have instituted similar mandates, and Congress is now considering the Mental Health Parity Act of 2007. Similar motives compelled Congress to enact Medicare Part D, which provides comprehensive drug benefits and inspires many employers to offer generous insurance benefits to all of their employees.

Mandating or equalizing benefits for diverse populations in most cases does alleviate disparities in health insurance coverage - since demand for insurance is income-elastic, wealthier people are more likely to purchase more comprehensive coverage. But little is known about whether equalizing insurance benefits translates into equalizing levels of health services use. Given the popularity of mandating benefits, and knowing that insurance expansions ultimately reduce take-

Barak Richman (barakrichman@duke.edu) is an associate professor at the Duke University School of Law and a faculty affiliate at Duke's Social Science Research Institute, in Durham, North Carolina. 
home wages, understanding who benefits from comprehensive coverage is a criti cal, and long-overdue, area for rescarch.

This paper investigates the consumption of two important arcas of health care that are often subject to mandated insurance coverage and popular insurance expansions: pharmaceuticals and mental health care. It takes advantage of a unique data set that comprehensively documents health care use and its costs for a diverse population that enjoys equal insurance coverage and ready access to health care services. The data provide a rare opportunity to investigate differences in health care use when the unfortunately common inequalities in access to care are not present. It also offers a valuable window into understanding how vulnerable populations - who frequently are the intended beneficiaries of insurance mandatesactually fare when coverage is uniform across a heterogeneous population.

\section{Description of The Data}

- Health claims. Duke University and Duke University Health System provide health insurance to more than 20,000 employees in more than six counties in central North Carolina.' Duke Human Resources provided limited access to deidentified records of each employee's health claims for 2001-2004, yielding almost 92,000 per son year observations. Each claim includes information on the services provided, the associated diagnosis, and the amounts paid by both the insurer and the patient. The data also reveal each person's race, job category (from which education and in come are derived), and insurance benefits.?

- Demographic profile. The demographic profile of the population remained stable for the period under study. Approximately 68 percent of the sample was white and 24 percent was African American, the median annual income rose gradually from about $\$ 36,000$ to $\$ 40,500$ over the four years, and incomes at the seventyfifth and twenty fifth pereentiles ranged from approximately $\$ 47,800$ to $\$ 51,000$ and from $\$ 28,600$ to $\$ 30,500$, respectively. These figures roughly reflect the demographic profile of both Durham County (where Duke University is located) and the state of North Carolina. ${ }^{3}$

- Coverage options. Duke offers its employecs a menu of insurance coverage options for different employee paid premiums, including a health maintenance organization (HMO, selected by more than 70 percent of employecs), a more cxpensive preferred provider organization (PPO) with a wider network of participating providers (selected by about 15 percent of employees), and other managed care options, some of which were terminated and replaced during the period of study. The different plans offer slightly varying cost-sharing amounts for most medical services, and they also present different copayments for going to out of network providers. However, most offer the same package of drug and mental health benefits, in cluding identical copayments, tiering, and coverage, so there is far less variation across plans for these bencfits than in general. In 2004 , for example, three of the four available insurance plans, subscribed to collectively by 97 percent of Duke's employ. 
ees, offered identical drug benefits, and three of the four plans, subscribed to collectively by 87 percent of the employees, offered identical mental health/substance abuse benefits.

- Unlque resource. The data set offers an unusual opportunity to examine health care use when access is held constant across race and income. Most data sources on health care use, such as the Medical Expenditure Panel Survey (MEPS), rely on self-reported surveys of populations in which individuals have different insurance benefits and confront assorted barriers to care. In contrast, everyone in the Duke data set has comprehensive health insurance with nearly uniform drug and mental health coverage. Moreover, the Raleigh-Durham metropolitan area is home to many providers (including two academic medical centers), so people in the database live near a hospital and a physician practice. Also, because the data include Duke University Health System employees, a great number of these people work at or right next to health care institutions. Thus, the Duke population faces very few logistical and institutional barriers to care, and observed disparities in use can be attributed to other factors. ${ }^{4}$

\section{Hypotheses And Methods}

To examine the efficacy of insurance expansions designed to help disadvantaged people, the empirical tests examined whether low-income and nonwhite people use less of the mental health and drug benefits available to them than their high-income and white counterparts. Measuring use of benefits requires two distinct but related calculations: (1) the probability that a person will file a claim in a given year, and (2) given the probability of filing a claim, a person's estimated annual health spending. Since the relevant policy question asks who extracts benefits from insurance coverage, the empirical study focuses on the insurer's spending on behalf of individuals, rather than on individuals' out-of-pocket expenses.

The four years of data were aggregated into 92,000 person-year observations, with all dollar amounts converted into 2004 dollars. Ordinary least squares (OLS) regression estimated the probabilities that people would extract an insurance benefit within a given year. ${ }^{5}$ Then a two-stage smearing technique estimated annual individual spending. The two-stage technique first calculated a transformed estimation of annual spending only for those who exhibited positive spending, and then the mean of these smearing estimates was multiplied by the fraction of those who had positive spending. ${ }^{6}$ This two-part approach-rather than a onestep estimation of use-is appropriate when a sizable portion of the population has zero use, since a one-step estimation would then generate biased results. Control variables presumed to correlate with health care use were age, sex, years of education, and years of work experience. A dummy variable (exemption status) indicated whether the employee was an hourly or salaried worker, and individual dummy controls were also added for each of the available health insurance plans. Huber-White standard errors were generated to determine the statistical signifi- 
cance of the parameter estimates.

The regressions measured the effects of two distinct variables (race and income) on the use of two separate insurance benefits (mental health care and pharmaceuticals). Separate regressions were run on the usage data for each benefit. Regressions first examined the effect of race variables alone, then income alone, then both together (to determine whether the separate effects are independent), and then additional control variables were added gradually for a robustness check.

\section{Study Findings}

Although policymakers who mandate insurance benefits might think that equal insurance would equalize use of services, the regression results indicate otherwise. In these data, nonwhites and low-income people extracted fewer benefits than whites and high-income people did from the mental health and drug insurance coverage made available to them.

- Mental health benefits. Both race and income independently contribute to a person's likelihood of using mental health care (Exhibit l). The "Race only" model indicates that whites were significantly more likely than African Americans or Asians to file a claim for mental health benefits. ${ }^{7}$ When age and sex were controlled for, the race variables were highly significant and-in relation to the intercept-of very large magnitude. For example, a forty-year-old white male had an estimated probability of 7.5 percent of receiving mental health services within a year, while a fortyyear-old African American male had an estimated 1.l percent probability of receiving

\section{EXHIBIT 1}

Dependent Varlable: Probabillty Of At Least One Mental Health Claim In A Year in The Insured Sample, 2001-2004

\begin{tabular}{|c|c|c|c|c|c|}
\hline Model & Race only & $\begin{array}{l}\text { Income } \\
\text { only }\end{array}$ & $\begin{array}{l}\text { Race and } \\
\text { Income }\end{array}$ & $\begin{array}{l}\text { Race, Income, } \\
\text { and education }\end{array}$ & All varlables* \\
\hline Intercept & $0.077^{* * * *}$ & $0.028 * * * *$ & $0.071 * * * *$ & -0.011 & 0.0188 \\
\hline $\begin{array}{l}\text { Sex } \\
\text { Age }\end{array}$ & $\begin{array}{l}-0.022 * * * * \\
0.0005^{* * * *}\end{array}$ & $\begin{array}{l}-0.016^{* * * *} \\
0.0002^{*}\end{array}$ & $\begin{array}{c}-0.015^{* * * *} \\
0.0003^{* *}\end{array}$ & $\begin{array}{c}-0.014 * * * \\
0.0003^{*}\end{array}$ & $\begin{array}{l}-0.016 * * * * \\
0.0002\end{array}$ \\
\hline $\begin{array}{l}\text { African American } \\
\text { Asian }\end{array}$ & $\begin{array}{l}-0.064^{* * * *} \\
-0.059^{* * * *}\end{array}$ & & $\begin{array}{l}-0.060^{* * * *} \\
-0.058 * * * *\end{array}$ & $\begin{array}{l}-0.055 * * * * \\
-0.072 * * * *\end{array}$ & $\begin{array}{l}-0.056 * * * * \\
-0.069 * * * *\end{array}$ \\
\hline $\begin{array}{l}\text { Annual income } \\
\text { Education } \\
\text { Exemption status }^{\text {d }}\end{array}$ & & $0.0087^{* * * *}$ & $0.0026^{* * *}$ & $\begin{array}{l}-0.0043^{* *} \\
0.0077^{* * * *}\end{array}$ & $\begin{array}{c}-0.0073^{* * * *} \\
0.0062^{* * * *} \\
0.024 * * * *\end{array}$ \\
\hline
\end{tabular}

SOURCE: Duke Human Resources.

NOTES: Some of the claims in the data were for $\$ 0$. Probability estimations were made both for claims greater than $\$ 0$ and for claims of any amount, including $\$ 0$. Results were consistent and robust Estimates shown here are for claims of any amount.

a The "All variables" model Includes but does not show dummy controls for the available insurance plans and years of work experience; each model includes the race category of "Latino" and "other," but these results are not shown, either. For an explanation of why Latinos are removed from the sample, see Note 7 in text.

${ }^{\mathrm{b}}$ Male $=1$, female $=0$.

${ }^{\mathrm{c}}$ Annual income, in units of $\$ 10,000$.

"Salaried worker $=1$, hourly worker $=0$.

${ }^{*} p<0.10 * * p<0.05 * * * p<0.01 * * * * p<0.001$ 
such services, and a forty-year-old Asian male, 1.6 percent. These results remained extremely robust even as income, education, exemption status, and dummies for the insurance plans were added to the model.

Exhibit 1 also reveals that income has a significant and independent effect on seeking mental health care. An additional $\$ 10,000$ increased the likelihood of a person's receiving mental health care by nearly 0.9 percent, and this effect remained robust - through decreases in size-even after the race variables were added. The effect of income evaporates once education and exemption status are introduced into the analysis, as income is highly correlated with both. ${ }^{8}$ But since the primary policy question is whether insurance benefits facilitate regressive wealth redistributions, measuring consumption disparities by income-not confounded by education - is the research focus. In sum, the results suggest that race and income have independent and significant effects on use of mental health services. The race variables remained significant even after income and education were controlled for, and income remained significant even after race was controlled for.

- Insurance spending for mental health clalms. Of perhaps greater interest is how these differences in the propensity to seek care translate into disparities in receiving dollar benefits from insurers. Exhibit 2 indicates that whites could expect to receive nearly four times the annual insurance dollars that African Americans expected to receive and more than three times the dollars that Asians expected to receive. Similarly, people in the seventy-fifth income percentile received about twothirds more than those in the twenty-fifth percentile received. Similar to the results in Exhibit 1, both the race and income variables remained independently robust in the smearing estimates. ${ }^{9}$

Drug benefits. The same battery of regressions was performed on the data on pharmaceutical usage. Exhibit 3 shows the estimated linear probabilities that people would use insurance dollars to fill at least one prescription in a year. Here again, race and income had independently significant effects, although the magnitude of

\section{EXHIBIT 2}

Estlmated Annual Insurance Expenditures For Mental Health Clalms, Using TwoStage Smearing, In The Insured Sample, 2001-2004

\begin{tabular}{|c|c|c|c|c|c|c|}
\hline \multirow[b]{2}{*}{$\begin{array}{l}\text { Control } \\
\text { varlables }\end{array}$} & \multicolumn{3}{|l|}{ Race } & \multirow[b]{2}{*}{$\begin{array}{l}\text { Control } \\
\text { variables }\end{array}$} & \multicolumn{2}{|l|}{ Income } \\
\hline & White & $\begin{array}{l}\text { African } \\
\text { Amerlcan }\end{array}$ & Aslan & & $\begin{array}{l}\text { 25th } \\
\text { percentlle }\end{array}$ & $\begin{array}{l}\text { 75th } \\
\text { percentlle }\end{array}$ \\
\hline $\begin{array}{l}\text { Age, sex, race } \\
\text { Age, sex, race, income }\end{array}$ & $\begin{array}{r}\$ 62.97 \\
61.20\end{array}$ & $\begin{array}{r}\$ 17.68 \\
16.26\end{array}$ & $\begin{array}{r}\$ 20.60 \\
20.66\end{array}$ & $\begin{array}{l}\text { Age, sex, income } \\
\text { Age, sex, income, race }\end{array}$ & $\begin{array}{r}\$ 33.30 \\
33.87\end{array}$ & $\begin{array}{r}\$ 55.77 \\
55.83\end{array}$ \\
\hline $\begin{array}{l}\text { Age, sex, race, income, } \\
\text { education } \\
\text { All controls }\end{array}$ & $\begin{array}{l}66.07 \\
66.17\end{array}$ & $\begin{array}{l}16.34 \\
16.71\end{array}$ & $\begin{array}{l}13.27 \\
13.27\end{array}$ & $\begin{array}{l}\text { Age, sex, income, race, } \\
\text { insurance plans } \\
\text { All controls }{ }^{\mathrm{a}}\end{array}$ & $\begin{array}{l}33.74 \\
42.82\end{array}$ & $\begin{array}{l}56.48 \\
50.07\end{array}$ \\
\hline
\end{tabular}

SOURCE: Duke Human Resources.

- Including education and exemption. 


\section{EXHIBIT 3}

\section{Dependent Varlable: Probabllity of At Least One Pharmaceutical Claim In A Year, In The Insured Sample, 2001-2004}

\begin{tabular}{lccccc} 
& Race only & $\begin{array}{l}\text { Income } \\
\text { only }\end{array}$ & $\begin{array}{l}\text { Race and } \\
\text { Income }\end{array}$ & $\begin{array}{l}\text { Race, Income, } \\
\text { and educatlon }\end{array}$ & All variables* \\
\hline Intercept & $0.608^{* * * * *}$ & $0.590^{* * * *}$ & $0.636^{* * * *}$ & $0.645^{* * * *}$ & $0.646^{* * * *}$ \\
\hline Sex & $-0.183^{* * * *}$ & $-0.176^{* * * *}$ & $-0.175^{* * * *}$ & $-0.196^{* * * *}$ & $-0.193^{* * * *}$ \\
Age & $0.006^{* * * *}$ & $0.005^{* * * *}$ & $0.005^{* * * *}$ & $0.004^{* * * *}$ & $0.004^{* * * *}$ \\
\hline African American & $-0.051^{* * * *}$ & & $-0.055^{* * * *}$ & $-0.057^{* * * *}$ & $-0.058^{* * * *}$ \\
Asian & $-0.213^{* * * *}$ & & $-0.181^{* * * *}$ & $-0.191^{* * * *}$ & $-0.187^{* * * *}$ \\
\hline Annual income & & & $0.010^{* * * *}$ & $0.008^{* * * *}$ & $0.006^{* * *}$ \\
Education & & $0.015^{* * * *}$ & & 0.002 & 0.002 \\
Exemption status & & & & & 0.004 \\
\hline
\end{tabular}

\section{SOURCE: Duke Human Resources.}

"The "all variables" model Includes but does not show dummy controls for the available insurance plans and years of work experience; each model includes the race category of "Latino" and "other," but these results are not shown, either. For an explanation of why Latinos are removed from the sample, see Note 7 in text.

${ }^{\mathrm{D}}$ Male $=1$, female $=0$.

'Annual income, in units of $\$ 10,000$.

${ }^{\mathrm{d}}$ Salaried worker $=1$, hourly worker $=0$.

$* * * p<0.01 * * * p<0.001$

the disparity was much higher for Asians than for African Americans, particularly in comparison to the very high disparities that both races exhibited for mental health claims. The differences were sufficiently robust to suggest that at any given age, African Americans and Asians were less likely than whites to use their pharmaceutical benefits. To illustrate, a forty-year-old white male was estimated to have a 66.5 percent likelihood of having insurance pay for a prescription within a given year, whereas a forty-year-old African American male had a 61.4 percent likelihood, and a forty-year-old Asian male, 45.2 percent. These differences remained statistically significant (and, for African Americans, became more pronounced) as controls for income, education, exemption status, and insurance plans were added. In addition, the coefficient for income was positive and significant, as people became 1.5 percent more likely to use insurance-purchased pharmaceuticals for every additional $\$ 10,000$ in annual income, although the effect of income decreased (while remaining significant) as other control variables were added. ${ }^{10}$

- Insurance spending for drug benefits. These seemingly modest differences in the probabilities to file drug claims translate into quite significant differences in insurance spending. Exhibit 4 shows that African Americans, depending on the model, received \$140-\$225 less in insurance coverage than whites did. Asians received approximately $\$ 500$ less, extracting only one-quarter as many insurance dollars as whites. The usage differences between the twenty-fifth and seventy-fifth income percentiles are less stable. Consistent with the Exhibit 3 results, lower-income people extracted fewer insurance dollars than did those with higher incomes, but the differences diminished as other control variables were introduced." 


\section{EXHIBIT 4}

Estlmated Annual Insurance Spending For Pharmaceutlcal Clalms, Using Two-Stage Smearing, In The Insured Sample, 2001-2004

\begin{tabular}{|c|c|c|c|c|c|c|}
\hline \multirow[b]{2}{*}{$\begin{array}{l}\text { Control } \\
\text { varlables }\end{array}$} & \multicolumn{3}{|l|}{ Race } & \multirow[b]{2}{*}{$\begin{array}{l}\text { Control } \\
\text { variables }\end{array}$} & \multicolumn{2}{|l|}{ Income } \\
\hline & White & $\begin{array}{l}\text { African } \\
\text { American }\end{array}$ & Aslan & & $\begin{array}{l}\text { 25th } \\
\text { percentlle }\end{array}$ & $\begin{array}{l}\text { 75th } \\
\text { percentile }\end{array}$ \\
\hline $\begin{array}{l}\text { Age, sex, race } \\
\text { Age, sex, race, income }\end{array}$ & $\begin{array}{r}\$ 649.73 \\
682.78\end{array}$ & $\begin{array}{r}\$ 505.69 \\
487.66\end{array}$ & $\begin{array}{r}\$ 158.50 \\
190.09\end{array}$ & $\begin{array}{l}\text { Age, sex, income } \\
\text { Age, sex, income, race }\end{array}$ & $\begin{array}{r}\$ 587.16 \\
607.87\end{array}$ & $\begin{array}{r}\$ 628.79 \\
631.28\end{array}$ \\
\hline $\begin{array}{l}\text { Age, sex, race, income, } \\
\text { education } \\
\text { All controls }\end{array}$ & $\begin{array}{l}708.66 \\
707.13\end{array}$ & $\begin{array}{l}483.17 \\
483.78\end{array}$ & $\begin{array}{l}164.88 \\
168.13\end{array}$ & $\begin{array}{l}\text { Age, sex, income, race, } \\
\text { insurance plans } \\
\text { All controls } \mathbf{s}^{\mathrm{a}}\end{array}$ & $\begin{array}{l}609.01 \\
652.65\end{array}$ & $\begin{array}{l}630.90 \\
637.25 \\
\end{array}$ \\
\hline
\end{tabular}

SOURCE: Duke Human Resources.

- Including education and exemption.

\section{Discussion And Remaining Questions}

The results can be summarized as follows: Whites use more insurance-covered mental health and pharmaceutical services than African Americans and Asians, and high-income people use more of these services than do those with lower incomes. Thus, employer-sponsored insurance for these services disburses more insurance dollars to whites and high-income people than it does to nonwhites and lower-wage employees.

These findings, however, raise as many questions as they answer. Although it might be troubling that insurance coverage for these health services amounts to regressive wealth transfers, moving from these empirical findings toward policy implications requires first examining some other questions.

What might explain usage disparltles? The data provide little insight into explaining what produces the disparities in mental health care and pharmaceutical use, and different causal pathways would lead to different policy recommendations. For example, one set of pathways arises out of viewing health care delivery through the lens of a "gatekeeper" model, which focuses on the processes and hurdles a person must go through to obtain care. One important hurdle is out-of-pocket cost sharing. Even when copayments and coinsurance rates are identical across all insured people (as they are for mental health services and pharmaceuticals in most of the Duke sample), they likely will impose a greater burden - and have a greater deterrence effect-on the less affluent than on others. Thus, even identical copayments impose different barriers to care. ${ }^{12}$

Moreover, most mental health services and drug prescriptions can be obtained only after first seeing a primary care physician (PCP), which imposes additional copayments. For Duke insured employees, copayments for outpatient care, including visits to PCPs, vary across the different insurance plans, so employees having low-premium plans with higher copayments arguably face greater barriers to obtaining mental health care and pharmaceuticals. For this reason, the regres- 


\section{"If differences in use are a function of differences in preferences, then mandates in insurance should be heavily reconsidered."}

sions for mental health and pharmaceutical used included dummy variables for the different health plans, so that any variation that is explained only by the differences in insurance coverage is theoretically excluded. However, separate regressions that estimated the propensity to use outpatient care found similar consumption disparities across race and income, with nonwhites and lower-income people exhibiting lower likelihood of seeking outpatient care (results not shown). This suggests that disparities in seeking primary care might be driving different utilization rates of mental health and pharmaceutical benefits. In short, it is unclear whether or not people are deterred from visiting a PCP or from seeking pharmaceuticals or mental health services.

Another cause of use disparities might come from the gatekeeper itself. An expansive survey by the Institute of Medicine revealed that racial minorities are less likely than whites to receive referrals and costly treatments for a large range of services, even when insurance coverage is equal. ${ }^{13}$ If these mechanisms explain use disparities, then providers' practices (rather than the structure of insurance benefits) should be the target of reform efforts.

Alternatively, differences in use patterns might reflect differences within the population-including different attitudes toward and preferences for care. This analytical lens might be termed a "consumer" approach to understanding health care use. Attitudes toward mental health care and perceptions of mental illness, which certainly affect a person's behavior as a consumer of health services, have been shown to vary considerably by race. The U.S. surgeon general suggested in an important 2001 report that despite the widespread benefits of mental health care, "the stigma surrounding mental illness is a powerful barrier to reaching treatment" and that racial and ethnic backgrounds greatly affect the stigma associated with mental illness. ${ }^{14}$ If traditional mental health care is as advantageous as the surgeon general's report suggests, then it might be more beneficial to address these perceptions of mental illness and mental health care while maintaining equal and expansive insurance benefits. Some have similarly suggested that diversifying the medical profession would reduce the stigma attached to mental illness and perceived barriers to care, and thus deserves to be a policy priority. ${ }^{15}$

However, the surgeon general's 2001 report also suggests that different racial and ethnic minorities ascribe different values to, and thus have different preferences for, traditional health care. For example, racial minorities might turn to alternative medicines instead of traditional pharmaceuticals, or to communitybased social support rather than to doctor-facilitated mental health care. ${ }^{16}$ If differences in use are a function of differences in preferences, rather than differences in access, then mandates in insurance should be heavily reconsidered. 
These trade-offs highlight how mental health care and pharmaceuticals can substitute for, and be substituted by, other resources and services. The $\$ 64,000$ question is which health services offer the most cost-effective benefits. Further exploration of the Duke claims data and similar data might help answer that question. For example, broader analyses of individual total health care use might reveal whether mental health services are being substituted for by equally effective social support or by more expensive inpatient care. ${ }^{17}$ Inquiries into other employer data, such as metrics for workers' productivity and well-being, might offer other opportunities to explore the effectiveness of different forms of care and insurance coverage.

In short, there is much more to learn from a consumer approach to health care. However large and insightful the literature on consumer-driven health care has become, it still is not well known to what degree consumer heterogeneity is a function of different preferences (to which benefit policies should accommodate) or harmful perceptions and stigmas (which benefit policies might want to combat). This difference is especially important when legislatures consider mandating insurance coverage for certain health services. At the very least, the empirical findings here should cause the health policy community to question whether insurance expansions, employers, or advocacy groups might induce people in vulnerable populations to use the services that policymakers want them to use.

Does mandated coverage alleviate health disparltles or protect against calamity? The findings here suggest that equal coverage of mental health care and pharmaceuticals is unlikely to lead to equal use. If policymakers hope, for example, to mitigate the nation's disparities in mental health care across race and class, they should be forewarned that insurance mandates might instead heap greater benefits on an unintended and already privileged population. ${ }^{18}$

Advocates for mental health parity might nonetheless claim that mandated benefits would alleviate mental health disparities even if they exacerbate disparities in mental health care use. Although these findings certainly challenge the conventional wisdom that underlies mental health parity, they do not intimate how use of mental health care translates into improvements in mental health, and the marginal benefits from mental health care might be higher for certain demographic groups, or for people who are otherwise unlikely to seek mental health care, than for others. Thus, even if insurance benefits translate into more insurance dollars accruing to whites and those with high incomes, it might lead to greater improvements in mental health for nonwhites or people with low incomes.

These results also invoke the weighty question of what health insurance is really for. By quantifying the dollars distributed by insurance coverage, the results indicate that health insurance plays an important (and, perhaps, regressive) role in redistributing income. This approach neglects the traditional view of health insurance qua insurance, which is designed to pool risk and provide support to those who suffer misfortune. But the findings do not even square with this vision 


\section{"These findings raise serious questions about the efficacy and fairness of mandating mental health and pharmaceutical benefits."}

of health insurance, since it is unlikely that whites and those with high incomes are at greater risk of financial catastrophe from illness, and thus in greater need for these health services, than nonwhites and those with lower incomes. Nonetheless, it should be further explored as to how health insurance offers true insurance against adversity versus how it instead is a form of prepaying for certain health services, and which insured services fulfill which of those two roles. For services that fulfill the latter role-and mental health and pharmaceutical benefits likely do-an investigation of the distributional benefits is highly important.

Who pays for coverage mandates? If use disparities in mental health care and pharmaceuticals are a simple function of preferences, then these services would seem to be services that nonwhite and low-income consumers simply do not want. Are they nonetheless forced to pay for them? It would indeed be very unfair if lowincome and historically disenfranchised racial minorities were required to pay insurance premiums for services that primarily benefit more-affluent whites. ${ }^{19}$

Answering this critical question ties into the larger question of who ultimately pays for health insurance. Employee contributions to health insurance premiums are uniform for all employees, irrespective of race and income, and there is general consensus that an employer's contribution is ultimately borne by the employees in the form of lower wages. ${ }^{20}$ The question, then, is how employers pass on to employees the portion of the insurance premiums they pay on their employees' behalf: Do employers reduce each employee's take-home pay in roughly equal amounts, or is each employee's take-home pay adjusted for the amount of benefits that employee uses?

In an efficient labor market, an employee's total compensation-wages plus benefits received-is equal to the value of his or her productivity, so if an employer attempts to pass on more than the cost of the health benefits that the employee uses, the employee would seek employment elsewhere. This would suggest that employees only pay for the insurance they desire and are expected to use, and not for the use of others. ${ }^{21}$

It could be argued, however, that a labor market with this degree of fluidity relies on near-heroic assumptions about employees' perceptions of their opportunity costs and employers' nimbleness in distributing health premiums based on employees' usage. A more grounded perspective is that employers estimate their own share of employees' health premiums-the share they pass on-by dividing their total cost of insurance by their number of covered employees, thus imposing equal payments on all employees.2. If employers pass on costs in this way, and all low-use employees do not immediately jump to other employment opportunities, then certain employees do pay for services they do not use, and health insurance 
effectively orchestrates transfer payments from low to high users. Ultimately, how employers pass on health insurance costs is also an unresolved and potentially important empirical question. Unlocking internal accounting practices could identify transfer payments from one group of employees to another.

\section{Concluding Remarks}

This study examined whether there are race and income disparities in health care use even when health insurance coverage and access to health services are held constant. The results indicate that whites and high-income people use more mental health care and pharmaceuticals than nonwhites and those with lower incomes. White and affluent workers consequently extract more insurance dollars for these benefits than their nonwhite and lower-income coworkers.

- Study IImitations. The limitations of these results should be recognized. The studied population works in a university setting, and it is unclear how generalizable the findings are. Because use disparities are found even though each person in the sample enjoys comprehensive health insurance and access to health care providers, disparities across race and class in most other populations are probably even higher than those found here. However, it is alternatively possible that white and highincome workers in university settings are unusually high users of mental health care and pharmaceuticals. It also is unclear how applicable these results are to other health care services that are commonly mandated by policymakers (although some, such as infertility treatment, likely would produce similar patterns).

Unclear pollcy Implications. More important, it is not clear what interventions should follow from these results. The potential causes for the use disparities range from different attitudes toward necessary care to discriminatory referral practices to different preferences and needs for care. Moreover, it is unclear how use disparities affect health disparities and whether the labor market ultimately compensates those who use few of their insurance benefits. The results do not indict any specific actor in the health care system and might suggest the need to intervene at each level of health care delivery-the provider, the insurer, and the consumer. Much more needs to be known about how people engage with their insurance benefits and health care providers and whether those benefits and providers meet such people's needs. Further research using employer claims data could shed light on these questions.

- Serlous questlons ralsed. Nonetheless, these findings raise serious questions about the efficacy and fairness of mandating mental health and pharmaceutical benefits, as Congress (like many state legislatures) has done and is apt to do again. They suggest that insurance of this kind might amount to transfer payments from nonwhites to whites, and from low-income to higher-income workers. Before insurance expansions spread further, there should be additional investigation as to whether they effectively extract resources from low-use groups to benefit the more affluent, and whether they ultimately bring harm to the people they are designed to help. 
The author owes enormous debts of gratitude to Frank Sloan and Melissa Guerrero Witt for their many consultations and superior statistical assistance; to John Dement, who made the original data available; to Duke Human Resources, which has becn a supportive partner in this research; and to Duke's Social Science Research Institute Faculty Fellows, who provided early momentum to this project. The project was made possible by funding from Duke's Provost Common Fund.

\section{NOTES}

1. Duke has employees living in 97 of North Carolina's 100 counties, but 95 percent live in the six counties surrounding the Raleigh Durham area. The region is home to many urban, suburban, and rural residential areas.

2. To protect employees' privacy, and to ensure that the data remained deidentified, individual salaries were not released. However, the Duke Human Resources Department categorizes cach position by job code, each with a fairly precise salary range and required levels of education, which permitted imputing education and annual income for each person. Income was determined by the midpoint of the income range for each job code, coded in units of $\$ 10,000$ in 2004 dollars. For job codes where wages are hourly, the hourly rate was multiplied by the individual's full-time equivalent. Job code salary ranges were not available for 2001, so 2001 incomes were imputed for each job code from the salary ranges in 2002-2004. Finally, faculty members' salaries and the salaries of certain administrators are not determined by job code; thus, people in those positions were not included in the sample. Anecdotal evidence suggests that results would be even stronger if these high income workers remained in the data. Also omitted from the analyses were 784 people with missing data on race.

3. The data set is skewed by sex since women are heavily represented in health care occupations. Approximately 65 percent of the people in the data set were female. The median income for females in the sample was nearly identical to the median income for males, which is just above the median for males in Durham County.

4. It should be noted that the benefits staffs of most large employers should have access to similarly useful data, but very few share their data with researchers. Medicare claims data exhibit some of these advantages, since they follow heterogeneous people with known insurance benefits, but those data do not cover the working population.

5. Logit estimations were also used to estimate the probabilities of use, and the same variables were found to be statistically significant. Ordinary least squares (OLS) regression was used instead because of the ease of interpreting OLS coefficients. Some of the claims in the data were for $\$ 0$. Probability estimations were made both for claims greater than $\$ 0$ and for claims of any amount, including $\$ 0$. Results were consistent and robust. Estimates shown are for claims of any amount.

6. The smearing estimate is $\left.\left[\exp \left(X_{0} \beta\right) \times n^{-1} \Sigma \mid \exp \left(e_{i}\right)\right]\right]$ where $X_{0} \beta$ is the predicted values from an OLS regression of log dollars consumed and $e_{i}$ is the residuals from that regression. This is the same two-stage smearing estimation method used in W.G. Manning et al., "Health Insurance and the Demand for Medical Care: Evidence from a Randomized Experiment," Amcrican Economic Review 77. no. 3 (1987): 251-277.

7. The Latinos in the data set appear to be misrepresentative of other Latinos in Durham and North Carolina. Median incomes for Latinos in the sample held steady at approximately $\$ 34,000$ throughout the sample, just slightly below the overall median, and Latinos median education was at least one year higher than the sample's overall median. Many Latino low-wage earners working at Duke are employees of subcontractors and not Duke employees, which might explain this skewed sample. Since few generalizeable conclusions can be drawn from studying the Latinos in the sample, results for that group are omitted.

8. Income and education have a correlation of $0.62(p<0.0001)$, and income and exemption status have a cor relation of $0.66(p<0.0001)$.

9. Duke also provides cmployees with short term counseling, or Personal Assistance Services (PAS), free of charge. Use of PAS was not captured in the claims data, but since this constitutes another form of employer-based mental health care, a complete understanding of employces' use of mental health care services requires taking PAS into account. Data on PAS usage were not at a level of detail that would allow a replication of the analyses executed on the claims data. Overview statistics of PAS use were available, and they suggested that the findings on race and income would not measurably change if PAS use were included in the larger sample. For example, PAS data revealed that white employees visited PAS in greater proportions than African American or Asian employees (no income data were available for PAS clients).

10. To ensure that patterns in mental health care use were not driving the results on pharmaceutical use, the 
effect of race and income were tested separately on the use of psychotropic and nonpsychotropic drugs. Results remained robust.

11. The RAND Health Insurance Experiment made important observations of how out-of-pocket payments affect use of health services. See J.P. Newhouse and the Insurance Experiment Group, Free for All?: Lessons from the RAND Health Insurance Experiment (Cambridge, Mass.: Harvard University Press, 1996). But there has been little research in this area since the RAND experiment, and the experiment focused on how cost sharing affects families with different incomes without substantial investigation into consumption patterns across race or ethnicity. Understanding how cost sharing affects use across different demographic populations is an important area for future research.

12. We tested but found no statistical significance for race-income interaction effects for either mental health care or pharmaceutical use.

13. B.D. Smedley, A.Y. Stith, and A.R. Nelson, eds., Unequal Treatment: Confronting Racial and Ethnic Disparities in Health Care (Washington: National Academies Press, 2003). See also K.A. Schulman et al., "The Effect of Race and Sex on Physicians' Recommendations for Cardiac Catheterization," New England Joumal of Medicine 340, no. 8 (1999): 618-626. If providers' discriminatory referral practices alone explain disparities in mental health and pharmaceutical use, one might expect to find no disparities across race for visits to PCPs, only disparities for the referred services. However, regressions on outpatient care find similarly regressive disparities by race and income. Of course, patients might anticipate discriminatory referrals and decide to forgo seeing a PCP in the first place.

14. United States Surgeon General, Mental Health: Culture, Race, and Ethnicity (Washington: U.S. Government Printing Office, 2001).

15. Sullivan Commission, Missing Persons: Minorities in the Health Professions, September 2004, http://minorityhealth.pitt.edu/archive/00000040/01/Sullivan_Final_Report_000.pdf (accessed 21 June 2007).

16. There is evidence, for example, that social support systems and religious participation provide some protection to the African American population from the causes of mental health disorders. See D.R. Williams and H.W. Neighbors, "Social Perspectives on Mood Disorders," chap. 9 in Textbook of Mood Disorders, ed. D.J. Stein, D.J. Kupfer, and A.F. Schatzberg (Arlington, Va.: American Psychiatric Publishing Inc., 2006), 145158.

17. Regressions on use of outpatient care indicated that whites and higher-income people in the sample used more outpatient care than nonwhites and those with lower incomes. Results from analyzing use of inpatient care, however, did not follow the same trend. This suggests that some people might obtain more preventive care to substitute for inpatient care. Mental health care and pharmaceuticals might similarly be more effective substitutes for other forms of expensive and disruptive inpatient care.

18. It deserves emphasis that major mental health disparities have been documented and deserve attention from policymakers. African Americans, for example, are overrepresented among people with very severe major depressive disorders and with persistent and debilitating mental illnesses. See D.R. Williams et al., "Prevalence and Distribution of Major Depressive Disorder in African Americans, Caribbean Blacks, and Non-Hispanic Whites," Archives of General Psychiatry 64, no. 3 (2007): 305-315.

19. See C.C. Havighurst and B.D. Richman, "Distributive Injustice(s) in American Health Care," Law and Contemporary Problems 69, no. 4 (2006): 7-82.

20. See, for example, J. Gruber, "Health Insurance and the Labor Market," Working Paper no. 6762 (Cambridge, Mass.: National Bureau of Economic Research, 1998).

21. See M.V. Pauly, "The Tax Subsidy to Employment-Based Health Insurance and the Distribution of WellBeing," Law and Contemporary Problems 69, no. 4 (2006): 83-101.

22. This accounting method was presumed by the White House when it contemplated how to implement the president's proposal to cap the tax exclusion on health insurance. L. Burman et al., "The President's Health Insurance Proposal: A First Look," Tax Policy Center Brief (Washington: Urban Institute and Brookings Institution, 23 January 2007). 